\title{
M-learning: Celulares utilizados como ferramenta didática numa escola pública de Ensino Médio
}

\author{
Alice A. Franco ${ }^{3}$, Ana Cristina M. da Costa ${ }^{1,3}$, Cláudia Valéria de A. Mota ${ }^{3}$, \\ Rejane L. L. Gadelha², Ricardo J. S. Graça \\ ${ }^{1}$ LASPI - Escola Politécnica - Universidade Federal do Rio de Janeiro \\ Caixa Postal 68.533 - 21.941-972 - Rio de Janeiro - RJ - Brasil \\ ${ }^{2}$ LIpE - Escola Politécnica - Universidade Federal do Rio de Janeiro \\ ${ }^{3}$ Secretaria de Estado de Educação do Rio de Janeiro - SEEDUC-RJ \\ \{aliceafrancolig.com.br, anacristina@poli.ufrj.br, \\ claudiamota2@bol.com.br, jullian@poli.ufrj.br, \\ rejanegadelha@poli.ufrj.br\}
}

\begin{abstract}
The diffusion and expansion of mobile phone plans to fulfill the demands of consumption made increase the use of mobile phones by the poorest classes of society. This phenomenon is a global trend generated by advances in the means of communication. The constant insertion of mobile technologies in the teaching and learning process has favored the emergence of research focused on the educational system. In Brazil, teachers have some resistance to incorporate new technologies. The classroom is still the place to turn off the phone. This paper makes a brief reflection on the cell phone use in formal education, especially in high school, with a case study.
\end{abstract}

Resumo. Com a difusão e ampliação dos planos de telefonia móvel para atender as demandas de consumo, o uso de aparelhos celulares encontra-se em plena expansão pelas classes mais carentes da sociedade. Esse fenômeno representa uma tendência mundial gerada pelos avanços nos meios de comunicação. A constante inserção dessas tecnologias móveis no processo de ensino e aprendizagem tem favorecido o surgimento de pesquisas voltadas ao ambiente educacional. Entretanto, no Brasil, os professores têm certa resistência em incorporar novas tecnologias. A sala de aula ainda é o lugar de desligar o celular. O presente trabalho faz uma breve reflexão sobre o uso do celular no ensino formal, principalmente no Ensino Médio, com um estudo de caso.

\section{Introdução}

A chegada das tecnologias móveis à sala de aula traz tensões, novas possibilidades e grandes desafios [Peres et al. 2013; Alves e Vieira, 2015; Silva et al. 2015; Moura 2014].

Segundo muitos professores, o uso dos aparelhos celulares é um problema constante em sala de aula. Muitos afirmam que o aparelho distrai o aluno, deixando-o sem atenção. Entretanto, mesmo antes dos celulares, a distração era uma das características apontadas pelos professores como causadora do baixo rendimento dos 
alunos. Houve uma redução considerável no valor de muitos aparelhos celulares devido à popularização deles na última década. Existem, hoje, muitas empresas de telefonia móvel no Brasil. Um aparelho celular pode, inclusive, chegar a sair de graça para o consumidor que adere a um plano específico de uma delas. Os aparelhos celulares evoluírem tanto a ponto de deixaram de ser apenas um aparelho telefônico e se tornarem pequenos computadores em que se pode instalar e utilizar aplicativos dos mais diversos.

As tecnologias móveis estão emergindo de um novo paradigma educacional a que se dá o nome de mobile learning (m-learning), isto é, aprendizagem através de dispositivos móveis [Moura 2010]. Mobile learning inclui muitos tipos diferentes de dispositivos portáteis sem fio. Se no início o conceito mobile learning estava centrado nas características de portabilidade e mobilidade dos dispositivos, esta ideia ampliou também à noção de mobilidade do usuário e da própria aprendizagem [Prensky 2001; Kukulska-Hulme 2005].

As funcionalidades do telefone celular como: dicionário, câmera, Bluetooth, SMS, jogos, calculadora, entre outras, podem ser usadas tanto para fins comunicativos quanto educativos. Em outras palavras, a tecnologia móvel pode aumentar a capacidade de aprendizagem dos alunos por meio destes dispositivos que parecem motivá-los para aprender também fora da escola.

Acredita-se que os alunos aprendem melhor e mais facilmente quando são dadas oportunidades de desenvolver habilidades para aprendizagem com tecnologias que lhes são familiares. Estamos vivendo, assim, em um contexto da computação ubíqua, no qual os celulares, em especial, estão incorporados em quase todas as atividades diárias. Então, por que não podemos tirar proveito desta situação? Por que não explorar as potencialidades deste dispositivo no processo de ensino-aprendizagem?

O presente trabalho faz uma breve reflexão sobre os enfoques ligados ao uso do celular no ensino formal, principalmente no Ensino Médio. Apresenta, ao final, um estudo de caso envolvendo o uso do celular num projeto de educação ambiental desenvolvido numa escola pública de Ensino Médio, no Rio de Janeiro, a partir de um curso de formação continuada de professores oferecido pelo Laboratório de Informática para Educação da Universidade Federal do Rio de Janeiro (LIpE/UFRJ).

\section{Celulares e o Ensino Médio}

Conforme o Caderno II (etapa 1), referente ao Pacto Nacional pelo fortalecimento do Ensino Médio [Brasil 2013], os jovens, em sua maioria, estão imersos na internet e ligados em seus celulares. A atual juventude está tão imersa nas tecnologias de informação que, por vezes, parece crer que a vida no passado seria impossível sem as facilidades tecnológicas do presente. De um modo geral, os jovens possuem maior familiaridade com as tecnologias que seus professores. E isso pode colocar em xeque a relação de poder e as hierarquias do saber na sala de aula.

Outras escolas, contudo, procuram aproveitar este universo cibercultural para dele extrair sentidos de participação e interesse para as atividades curriculares. Desta forma, a juventude interage crescentemente com as tecnologias e, assim, se produz, orienta seu comportamento e conduz a própria existência. Por isso se diz que os jovens de hoje são nativos digitais, uma geração nascida na era da internet [Brasil 2013]. Além 
disso, são considerados da "geração polegar", pela sua aptidão em escrever e enviar mensagens usando apenas os polegares. Estudos revelam que o polegar da geração mais nova está mais desenvolvido por causa das tecnologias [Moura 2014].

Assim, as manifestações culturais juvenis, notadamente as que se fazem pelas mídias eletrônicas, podem e devem ser utilizadas como ferramentas que facilitem a interlocução e o diálogo entre os jovens, profissionais da educação e a escola, contribuindo assim para o desenvolvimento de práticas pedagógicas inovadoras em comunidades de aprendizagens superadoras das tradicionais hierarquias de práticas e saberes ainda tão presentes nas instituições escolares [Carrano et al. 2013].

Dusek (2006) propõe uma abordagem da tecnologia a partir da proposição de Sistemas Tecnológicos. Como sistema, implica no envolvimento do homem com a tecnologia para ela funcionar [Dagnino 2008]. Fica clara a necessidade do envolvimento e participação dos alunos e professores, pois são eles que alimentam as atividades. Assim, apenas a inserção da tecnologia em processos de ensino-aprendizagem não garante eficiência e atualização. Em se tratando de tecnologia, o potencial não reside nela própria, e sim na interação com o homem. Desse modo, é preciso que os envolvidos, neste caso, alunos e professores, estejam preparados e dispostos, para que essa apropriação possa de fato representar transformação e gerar ganhos para a Educação [Fonseca 2013].

\section{O que diz a legislação do Estado do Rio de Janeiro}

Conforme a Lei do Estado do Rio de Janeiro n ${ }^{\circ}$ 5453, de 26 de maio de 2009, "fica proibido o uso de telefones celulares, walkmans, diskmans, Ipods, MP3, MP4, fones de ouvido e/ou Bluetooth, game boy, agendas eletrônicas e máquinas fotográficas, nas salas de aulas, salas de bibliotecas e outros espaços de estudos, por alunos e professores na rede pública estadual de ensino, salvo com autorização do estabelecimento de ensino, para fins pedagógicos". Isso quer dizer que em toda aula o professor deve pedir autorização?

O uso de dispositivos móveis para entretenimento e comunicação fora da sala de aula está perfeitamente generalizado pelos jovens. Porém, eles estão proibidos de usar os seus dispositivos móveis dentro da sala de aula. A ausência de computadores nas salas de aulas, bem como de laboratórios de informática em muitas escolas públicas, faz com que a atenção se volte para o uso dos celulares como ferramentas com potencialidades para apoiar o processo de ensino e aprendizagem [Moura 2014].

A análise do contexto das pesquisas confirmou a hipótese de que o uso de dispositivos móveis no ensino formal no Brasil é um campo de pesquisa bastante recente e que necessita ser consolidado [Almeida e Araújo 2013]. Conforme esses autores, a maioria das pesquisas propõe ou relata situações de utilização dos dispositivos no espaço restrito de uma sala de aula. Dessa forma, a mobilidade, uma das potencialidades desses recursos para o ensino, tem sido subutilizada. Fica evidente, pois, a necessidade de encorajar o processo de aprendizagem fora da sala de aula tradicional. Além disso, há necessidade de mais pesquisas que analisem o papel docente nesse processo, considerando que, conforme Adriani (2008) e Moura (2010), o 
V Congresso Brasileiro de Informática na Educação (CBIE 2016)

Anais do XXII Workshop de Informática na Escola (WIE 2016)

professor tem um novo papel na mediação pedagógica exigido pelo uso das tecnologias móveis na educação.

Apesar de ainda haver alguma resistência aqui ou ali, os governos de todo o mundo estão cada vez mais atentos sobre a necessidade de se colocar as tecnologias móveis, como celulares e tablets, a serviço da educação. A Organização das Nações Unidas para a Educação, a Ciência e a Cultura (UNESCO) publicou um guia com 10 recomendações políticas em que tenta ajudar governos a implantarem esses recursos nas salas de aula. Entretanto, a incorporação das tecnologias móveis ao ambiente educacional deve ser sempre um processo reflexivo e problematizador. Há risco de que possa haver algum interesse econômico com jogada de marketing para torná-la mais atrativa e vendável.

\section{CIEP 165: Parceria entre a Universidade e a escola}

Este trabalho foi desenvolvido no Centro Integrado de Educação Pública, CIEP-165 Brigadeiro Sérgio Carvalho, escola da Rede Estadual do Rio de Janeiro, que está localizado no Rio da Prata, sub-bairro de Campo Grande, situado na zona oeste do Município do Rio de Janeiro. O CIEP-165 abriga em média 1.500 (mil e quinhentos) alunos de Ensino Médio, entre eles jovens e adultos. O corpo docente é formado por 90 (noventa) professores que atendem às 40 (quarenta) turmas que a escola forma anualmente. Ele funciona com a modalidade de Ensino Médio Regular no horário diurno e de Educação de Jovens e Adultos (EJA) no noturno. É frequentado por um número representativo de moradores da região. O Rio da Prata é uma das portas de entrada do Parque Estadual da Pedra Branca que é uma das maiores florestas urbanas do mundo, com remanescentes de Mata Atlântica. O CIEP-165 Brigadeiro Sérgio Carvalho funciona como um pólo facilitador de ações de educação ambiental (EA) da região.

O laboratório de informática do CIEP-165 encontra-se em estado de abandono. Ele apresenta vários computadores fora de uso (obsoletos e sem manutenção) sem acesso à internet, ocasionando baixo interesse dos professores e alunos e pouca valorização do espaço dentro da escola.

Através de uma parceria com o Laboratório de Informática para Educação, da Universidade Federal do Rio de Janeiro (LIpE/UFRJ), foi possível a formação continuada de três (03) professores do CIEP-165, com o objetivo de promover a utilização crítica de novas tecnologias [Apple 1995], prioritariamente a informática, visando à melhoria do processo ensino aprendizagem de acordo com cada realidade educacional [Freire 1987]. As atividades do LIpE baseiam-se na Metodologia Participativa [Thiollent 1998; Thiollent 2006] e estão regularmente inscritas na PróReitoria de Extensão da UFRJ (PR-5). Assim, é possível a participação de alunos de graduação do curso de Engenharia Eletrônica e da Computação, através do recebimento de bolsas de extensão, no processo de revitalização da sala de informática das escolas. $\mathrm{O}$ Curso Tecnologia \& Educação, certificado pelo LIpE, possui o objetivo de apropriação de metodologias que tenham a tecnologia como meio das práticas pedagógicas.

A atividade proposta pelos professores que participaram do curso de formação continuada foi uma atividade de educação ambiental com a utilização do celular, baseada na metodologia francesa "La Main à la Patê - LAMAP" (Mão na Massa). Esta 
metodologia investigativa estimula a elaboração de hipóteses, ao mesmo tempo em que favorece um ambiente propício ao debate de ideias e ao desenvolvimento da capacidade de argumentação, através da confrontação de opiniões entre os educandos. Partindo sempre de desafios, são valorizadas as ideias iniciais, hipóteses e representações dos alunos sobre o tema. Eles são convidados a registrar, sistematicamente suas observações e a trabalhar em grupo, o que lhes dá a oportunidade de aperfeiçoar a argumentação, incitando-os a formular novas questões [Grynszpan 2002]. Trabalha sempre com uma pergunta desafio que, no caso em questão, foi: “O que é Mata Atlântica?". Nesse primeiro momento, os alunos responderam individualmente, depois em um pequeno grupo e, logo após, em um único grupo com todos. Houve a produção textual nas três etapas, utilizando um editor de texto no celular. No segundo momento, eles foram levados ao Parque Estadual da Pedra Branca, vertente do Rio da Prata, e a segunda pergunta desafio foi: "O que há de Mata Atlântica nesse local?". O registro deles tinha que ser realizado através da captação de imagens e sons, utilizando o celular. Logo após, os alunos foram estimulados a produzirem um vídeo.

\section{Resultados e discussão}

Apesar de um grande número de professores da Rede Estadual de Educação do Rio de Janeiro estar em greve e ao número reduzido de alunos circulantes na escola, inicialmente, apareceram 20 (vinte) alunos interessados em participar das atividades propostas. A participação deles foi voluntária. O celular apareceu como alternativa mais viável, principalmente por ser de fácil acesso para os alunos e, principalmente, gratuito para escola. A construção do conhecimento foi estabelecida por eles, pela troca de saberes entre o grupo. Criou-se um grupo pelo aplicativo "WhatsApp" e eles trocavam mensagens, informações, disponibilizavam imagens, músicas, vídeos, etc. Segundo Moura (2009), as tecnologias estão nas mãos dos alunos e, para eles, o futuro é móvel e expressar-se por meio do celular hoje é regra. Eles possuem competências comunicativas especiais que precisam e podem, através de estratégias inovadoras, serem transformadas em ações educativas.

Ao final do trabalho, dez (dez) alunos mostraram interesse em continuar participando das atividades do Laboratório de Informática. É um ponto positivo, levando-se em consideração que existe uma cultura na escola que o aluno para participar de qualquer atividade extraclasse, o professor deve oferecer algum tipo de compensação, como pontos no processo avaliativo. No trabalho em questão, nada foi oferecido aos alunos. Os que permaneceram, por afinidade, interesse e conhecimento, resolveram continuar por vontade própria.

O LIpE, além de oferecer o curso de formação continuada para professores da escola, acompanhou o projeto "in loco", dando suporte a todas sequências didáticas que foram desenvolvidas, dos planejamentos delas até a avaliação de todo processo, através da metodologia participativa [Thiollent 2005]. Os alunos da graduação do curso de Engenharia Eletrônica e da Computação participaram de todas as etapas e ajudaram na revitalização do Laboratório de Informática da escola, dando manutenção aos poucos computadores que puderam ser recuperados. A princípio, a proposta era utilizar como editor de imagens o "Movie Maker", mas os computadores, muito antigos, travaram no processo de edição. O celular mostrou-se, assim, uma ferramenta imprescindível e 
extremamente acessível para a realização desse trabalho. Toda produção de conhecimentos foi compartilhada entre professores e alunos da graduação, através da troca de saberes de todos envolvidos. Foi perfeitamente possível introduzir o celular à metodologia do "La Main à la Patê - LAMAP".

O estudo do entorno da escola é algo muito importante na Educação Ambiental. A escola está próxima ao Parque Estadual da Pedra Branca e muitos alunos não têm conhecimento dele. A atividade proposta mostrou que é possível estudar o bioma de Mata Atlântica de uma forma contextualizada, com o uso do celular. O próximo passo será disponibilizar o vídeo que foi produzido nas redes sociais para que a comunidade escolar tenha acesso ao material. Além disso, fazer um estudo dos problemas socioambientais do Parque pela vertente do Rio da Prata.

\section{Conclusões}

O acentuado crescimento tecnológico e o alto consumo de smartphones (telefones inteligentes com várias mídias num só aparelho) popularizam seu uso, em um público cada vez mais jovem. Para essa "geração polegar" que nasceu submersa na tecnologia móvel, fazer o uso dos recursos disponíveis pode ser produtivo e eficiente no ambiente escolar.

O objetivo é tirar o melhor proveito dos milhares de celulares disponíveis, usados pela maioria como meio de comunicação, principalmente dos alunos, e inseri-los no contexto de ensino e aprendizagem como uma ferramenta didática. Porém, sempre com uma visão crítica dessa apropriação no processo educacional.

O fato é que o celular é uma tecnologia gratuita para a escola. Se o computador ainda é um objeto restrito, o celular está presente em boa parte das escolas nas mochilas dos alunos de diferentes classes sociais. Muitos professores, entretanto, ainda não conseguem vislumbrar o uso do celular a uma aprendizagem eficaz. Talvez por falta de capacitação (formação continuada), falta de tempo para planejamento ou por medo do novo. Mesmo que o uso do telefone celular seja proibido por lei e pela escola, ele pode se tornar um recurso pedagógico de grande importância no contexto escolar, mas não será de um dia para outro. Há ainda necessidade de se encorajar o processo de aprendizagem fora da sala de aula tradicional, visto que o uso desses recursos ainda está restrito, na maioria dos casos, ao espaço físico de uma sala de aula.

\section{Referências}

Peres, A., Milleto, E. M., Kapusta, S. et al. (2013) "Monitoramento da Qualidade da Água, Redes Sociais das Coisas e a Educação Ambiental”. In: Anais do II Congresso Brasileiro de Informática na Educação e XXIV Simpósio Brasileiro de Informática na Educação.

Alves, E. D. G. e Vieira, M. F., (2015) "Celular e sala de aula: dos limites às possibilidades". CBIE-LACLO 2015. In: Anais do XXI Workshop de Informática na Escola. 
V Congresso Brasileiro de Informática na Educação (CBIE 2016)

Anais do XXII Workshop de Informática na Escola (WIE 2016)

Silva, F., Silva, J. S., Lucena M. et al. (2015) "Requisitos para Integração entre Ambientes de Aprendizado e m-Learning: uma Revisão Sistemática da Literatura". In: Anais do XXVI Simpósio Brasileiro de Informática na Educação.

Moura, A. M. C. (2014) "Geração Móvel: um ambiente de aprendizagem suportado por tecnologias móveis para a Geração Polegar". Disponível em:<http://adelinamouravitae.com.sapo.pt/gpolegar.pdf $>$. Acesso em: $23 \mathrm{de}$ setembro de 2014.

Moura, A. M. C. (2009) "O Telemóvel para Ouvir e gravar Podcasts: exemplos no Ensino Secundário". Disponível em: http://docplayer.com.br/16342458-O-telemovelpara-ouvir-e-gravar-podcasts-exemplos-no-ensino-secundario.html. Acesso: 01 de junho de 2016.

Moura, A. M. C. (2010) "Apropriação do Telemóvel como Ferramenta de Mediação em Mobile Learning: Estudos de Caso em Contexto Educativo". Tese de DSc. Universidade do Minho, Ciências de Educação, na Especialidade de Tecnologia Educativa. Braga, Portugal.

Prensky, M. (2001). "Digital Natives, Digital Immigrants". On the Horizon, v. 9, no. 5, pp. 1-5, http://www.marcprensky.com/writing/default.asp. (Acessível a 29 de Abril de 2009).

Kukulska-Hulme, A. (2005). Introduction. In Kukulska-Hulme, A. \& Traxler, J. (eds). "Mobile Learning: A Handbook for Educators and Trainers". London: Routledge, pp. 1-6.

BRASIL (2013) Secretaria de Educação Básica. Formação de Professores do Ensino Médio, Etapa I - Caderno II: “O Jovem como Sujeito do Ensino Médio". Ministério da Educação, Secretaria de Educação Básica; Organizadores: Paulo Carrano, Juarez Dayrell. Curitiba: UFPR/Setor de Educação.

Carrano, P.; Damasceno, P. A. e Takakgi, C. (2013) "A escola tem tudo o que precisamos. O Facebook tem tudo o que gostamos: Estudo de caso sobre as redes sociais de internet numa escola pública de Ensino Médio". In: Seminário Internacional. As Redes Educativas e as Tecnologias: Transformações e Subversões na Atualidade, 7.. Rio de Janeiro: UERJ.

Dusek, V. (2006) "O que é tecnologia? Definindo ou caracterizando tecnologia". In: Filosofia da Tecnologia. São Paulo: Edições Loyola, 2006.

Dagnino, R. (2008) "Neutralidade da ciência e determinismo tecnológico". Campinas, SP: Editora Unicamp, 2008.

Fonseca, A. G. M. F. (2013) "Aprendizagem, Mobilidade e Convergência: Mobile learning com Celulares e Smartphones". Revista Eletrônica do programa de PósGradualão em Mídia e Cotidiano. N² 2, PP. 265-283.

Almeida, R. R., Araújo Jr., C. A. F. (2013) “O Uso de Dispositivos Móveis no Contexto Educativo: Análise de Teses e Dissertações Nacionais”, Revista Tempos e Espaços em Educação, v. 6, nº. 11, pp. 25-36.

Adriani, R. L. S. B. (2008) "Jogos e M-learning: do veículo de comunicação ao instrumento de ensino". Dissertação de Mestrado. Pontifícia Universidade Católica 
V Congresso Brasileiro de Informática na Educação (CBIE 2016)

Anais do XXII Workshop de Informática na Escola (WIE 2016)

de São Paulo, Programa de Comunicação e Semiótica da Pontifícia Universidade Católica de São Paulo. São Paulo, Brasil.

Apple, M W. (1995) "Trabalho Docente e Textos: Economia Política das Relações de Classe e Gênero em Educação”. Porto Alegre: Artes Médicas.

Freire, P. (1997) "Pedagogia da Autonomia: Saberes necessários à prática educativa”. $4^{\text {a }}$ Edição. Rio de Janeiro: Ed Paz e Terra.

Thiollent, M. (1998) "Extensão Universitária e Metodologia Participativa". $1^{\mathrm{a}}$ ed. Rio de Janeiro: COPPE/UFRJ.

Thiollent, M. (2006) "A Inserção da Pesquisa Ação no Contexto da Extensão Universitária”. In: BRANDÃO, Carlos R., STRECK, Danilo R., orgs. Pesquisa participante: o saber da partilha. Aparecida/SP: Idéias \& Letras.

Grynszpan, D. (2002) "Conhecendo o Projeto ABC na Educação Científica - Mão na Massa". http://www.ioc.fiocruz.br/abcnaciencia/html/word/?page_id=2. Acesso em 30 de maio de 2016.

Thiollent, M. (2005) "Metodologia da Pesquisa-Ação", São Paulo: Cortez Editora, 14a ed. 